\title{
The role of agrarian science in transforming methods of using the Earth remote sensing data into publicly available technology
}

\author{
Viktor I. Medennikov ${ }^{1}$, Yuri A. Flerov ${ }^{1}$ \\ ${ }^{1}$ Federal Research Center "Computer Science and Control” of the Russian Academy of Sciences, Moscow, Russia
}

\begin{abstract}
Improvement of the Earth remote sensing technology has led to an active implementation of its results in many areas of human activity with a significant expansion of both the number of industries using remote sensing data and the range of problems to be solved. Agriculture is perhaps the only industry where there is a symbiosis of this data obtained from both spacecraft, unmanned aerial vehicles, and ground vehicles with a significant intersection of information used in many sectors of economy, such as cartography, ecology, land management, logistics, construction, weather and climate, etc. Such an integrated use of heterogeneous information from various sources requires developing a digital decryption tool (standard) in the form of a unified geographic information system and a unified conceptual information model of crop production. From such a geographic information system, users could obtain unified digitized images, which would be ready for use and entering into their databases, whereas a unified conceptual information model of crop production, integrating all the knowledge of this industry, should turn into a kind of a publicly available technology. On the other hand, digitalization of the economy has significantly expanded the range of problems to be solved not only in production, but also in science, allowing for purely theoretical scientific research to actively penetrate into production. This also requires appropriate digital standards and managerial structures.
\end{abstract}

\section{Keywords}

Earth remote sensing, agrarian science, publicly available technology.

\section{Introduction}

Over the past decades, the use of Earth remote sensing (ERS) data has made unprecedented progress in engineering and applied terms, especially in recent years, when there has been a quantum leap in image acquisition means, primarily in optoelectronic equipment and image processing software. The ERS technology is developing so rapidly that it is difficult for potential users to stop when choosing a starting point for its use, being confident that more advanced and cheaper technology will appear in the near future. This progress has led to an active implementation of ERS data in many areas of human activity with a significant expansion of the range of problems to be solved, from monitoring to automatic decision making based on artificial intelligence [1].

This new opportunity also requires the involvement of a significantly larger amount of necessary information, both direct industry-specific data and data coming from related industries.

SDM-2021: All-Russian conference, August 24-27, 2021, Novosibirsk, Russia

$\bigoplus$ dommed@mail.ru (V. I. Medennikov); yflerov@yandex.ru (Y. A. Flerov)

(c) (1) $\odot 2021$ Copyright for this paper by its authors. Use permitted under Creative Commons License Attribution 4.0 International (CC BY 4.0).

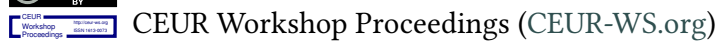


For this purpose, the basic requirement of the digital economy should be fulfilled in the form of integrating both industry information systems (IS) and intersected information resources (IR) based on some new developed digital standards as a result of market interaction between economic agents, or through the efforts of government bodies.

Since ERS data began to be actively used in many sectors of the economy, such as cartography, ecology, forestry and agriculture, land management, geology, logistics, construction, pipeline systems, weather and climate, oceanology, etc., upon creating appropriate digital standards, they should gradually acquire the status of publicly available infrastructure technology, similar to the role of railways, electrical grids, telegraph and telephone communications. This idea was first suggested by David Paul [2]. Therefore, this paper considers the methodological foundations and prerequisites for such a transformation of the ERS technology using the example of agriculture, since this industry, due to the spatial and temporal nature of its activities in vast territories, makes it possible to apply, on the one hand, the ERS data from most of its sources, and on the other hand, it has the property of significant intersection of the information used with the information circulating in many of the above economy sectors. Thirdly, the digital economy (DE) has raised a huge layer of scientific information, that was previously purely theoretical, which, under certain conditions, can become a so-called complementary asset for the ERS technology.

\section{Evolution of integration technology for economy informatization}

To consider the transformation of the ERS technology into a publicly available asset, let us analyze the main requirement of the DE in the form of integrating both ISs and IRs used to solve its problems. This requirement is a result of the evolution of developing global information means. During this evolution, once the data has been separated from the software, with the advent of more powerful means for data storing, processing, and transmitting, we faced a need to replicate ISs to a certain range of companies. In our opinion, the IS design technology have gone through four evolutionary stages in its life cycle, and each of these stages was marked by a significant transformation of data storage, transmission, processing, and integration methods and software, based on the fact that the IS design space of each firm (from $1^{\text {st }}$ to $N^{\text {th }}$ ) includes three main measurement axes: IRs, applications (automated tasks), and tools, representing system-wide software and electronic equipment (Figure 1).
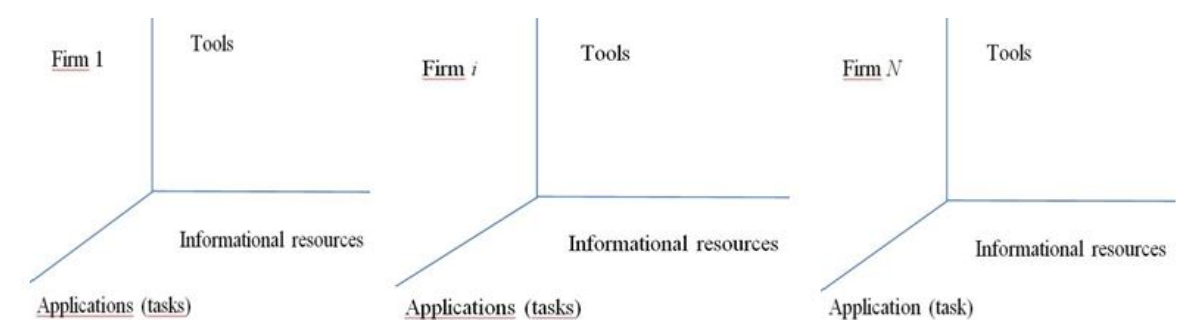

Figure 1: Project space of information systems. 
In the ISs of the first stage, almost all developed software was focused either on the needs of a particular company or the needs of a narrow range of similar businesses. This required significant costs for its support. It was the traditional, so-called task-by-task approach. At the second stage, with the improvement of information and communication technology (ICT), which led to standardization, cooperation, integration, and reduction of software costs, the functionality of the systems was expanded. This process made it possible to optimize the management functions and information processing methods. The third stage is associated with the emergence of local area networks (LAN) and database management systems (DBMS). At this stage, both software and data were physically and logically separated from specific computing facilities and hosted on virtual computers in LAN nodes. At the same time, starting from the second stage, there has been an economic feasibility of replicating ISs to a certain range of companies.

The variety of information technologies used (most of them being ontologically and functionally incompatible), have turned the largely theoretical problem of integrating IRs, applications, and tools into an extremely urgent task in economic and practical terms of integrating them in a unified information and management environment in the transition to the fourth stage of the IS evolution associated with the DE. This problem cannot be solved without agreeing upon digital standards for all axes of the IS design space, which should be based on methods of ontological modeling of applications (knowledge, problems) and IRs, that would allow to connect them, having a mostly heterogeneous structure, into a single information space.

Research and development in the field of ontological modeling is actively developing all over the world due to the transition to the fourth stage of the IS evolution, as well as the ideas of semantic technology, knowledge spaces, and Semantic Web. Therefore, the research in the field of models and methods for merging and aligning ontologies is especially in demand [3].

Let us formalize the main requirement of the DE in the form of integrating both ISs and IRs used to solve its problems. To do so, we have introduced the following notation: $m$-industry code; $j$ - sub-industry code; $k$ - subject area code; $i$ - company code; $n$ - problem code; $l_{m j k i n}$ - IR information element, $l_{m j k i n} \in L ; z_{m j k i n}-$ the index of problems, which takes the value 0 or 1 depending on the existence of the $n^{\text {th }}$ problem in the corresponding set $z_{m j k i n} \in Z$; $d_{m j k i n}-$ design tool for the corresponding IS, $d_{m j k i n} \in D ; A_{l}\left(l_{m j k i n}\right)$ operator of ontological modeling of IRs, which represents the entire set $L$ in the form of

$$
L=L_{1} \mathrm{Y} L_{2} \mathrm{Y} L_{3} \mathrm{Y} L_{4} \mathrm{Y} L_{5},
$$

where $L_{1}$ is a set of IRs that includes ontologically uniform information elements $l_{m}^{1}$ for the whole industry $m, l_{m}^{1} \in L_{1}, L_{2}$ is a set of IRs that includes ontologically uniform information elements $l_{m j}^{2}$ for the $j^{\text {th }}$ sub-industry of industry $m, l_{m j}^{2} \in L_{2}, L_{3}$ is a set of IRs that includes ontologically uniform information elements $l_{m j k}^{3}$ for the $k^{\text {th }}$ subject area of the $j^{\text {th }}$ sub-industry of industry $m, l_{m j k}^{3} \in L_{3}, L_{4}$ is a set of IRs that includes ontologically uniform information elements $l_{m j k i}^{4}$ for the $i^{\text {th }}$ company of the $k^{\text {th }}$ subject area of the $j^{\text {th }}$ sub-industry of industry $m$, $l_{m j k i}^{4} \in L_{4}, L_{5}$ is a set of IRs that includes ontologically uniform information elements $l_{m j k i n}^{5}$ only for the $n^{\text {th }}$ problem for the $i^{\text {th }}$ company of the $k^{\text {th }}$ subject area of the $j^{\text {th }}$ sub-industry of industry $m, l_{m j k i n}^{5} \in L_{5} ; A_{z}\left(z_{m j k i n}\right)$ is the operator for ontological modeling of problems, 
which represents the entire set $Z$ in the form of

$$
Z=Z_{1} \mathrm{Y}_{2} \mathrm{Y} Z_{3} \mathrm{Y}_{4} \mathrm{Y} Z_{5},
$$

where the meaning of the problem set $Z_{i}(i=1, \ldots, 5)$ is similar to the above expression (1).

Similarly, let us define the classification operator for the IS design as $A_{d}\left(d_{m j k i n}\right)$, where

$$
D=D_{1} Y D_{2} \mathrm{Y} D_{3} \mathrm{Y} D_{4} \mathrm{Y} D_{5} \text {. }
$$

Due to the lack of space, we will not detail the operators $A_{z}\left(z_{m j k i n}\right)$ and $A_{d}\left(d_{m j k i n}\right)$. Let us present the IS design operator in the DE as $P\left(A_{l}\left(l_{m j k i n}\right), A_{z}\left(z_{m j k i n}\right), A_{d}\left(d_{m j k i n}\right)\right)$, and some criterion of the IS design efficiency as

$$
W\left(P\left(A_{l}\left(l_{m j k i n}\right), A_{z}\left(z_{m j k i n}\right), A_{d}\left(d_{m j k i n}\right)\right), R, G\right)
$$

where $R$ means the resources allocated for the design, $G$ means various kinds of restrictions, the main of which include restrictions on the so-called complementary assets in the form of a managerial structure and the human capital development level [4].

Depending on the methods and models used in the IS design, there are individual, standard, and computer-aided designs. In the DE, when the development of ICT allows for a reasonable level of integration of both IRs and tasks through optimizing the criterion $W$, the solution of the following problem is of great importance: by choosing a suitable design operator $P$, to achieve the specified values of the IS parameters. The above formalized rationale for transition to methods of integration and standardization in the development of ISs in the agro-industrial complex (AIC) served as the basis for developing a mathematical model to create a digital platform for managing the industry's economy, the calculation results for which will be considered in the next section [7].

At one time, the ratios under consideration were given a numerical confirmation translated visually in the form of the so-called Brooks square [5], as shown in Figure 2.

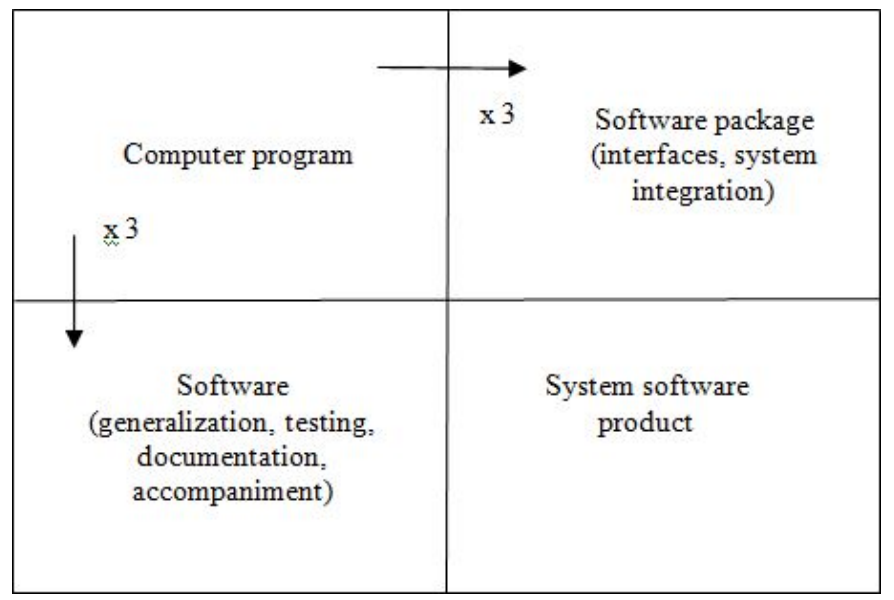

Figure 2: Brooks square. 
The Brooks square shows data on the increase in costs during the transition from software development based on original design to a software product and its integration into a software package. It follows from the figure that, when upon transition to a unified digital platform (DP), the cost of a software product replicated and integrated into some ISs is an order of magnitude higher than the cost of developing original software. Therefore, investments in integrated ISs will provide a level of development self-sufficiency during their implementation starting from the second dozen companies, the huge economic effect of which is most obvious for industries with a large number of companies, such as agriculture. In this case, the benefits of an integrated approach are so great that their users are already showing a willingness to adapt their local interests, driven by the flexibility and cost-effectiveness of business practices that have been used for many years, to standardized management functions in new digital technology.

Whereas, at the second and third stages, the economic and technological feasibility of integration processes led to the emergence of international management standards such as ERP, which are only a methodology, in the last 2 or 3 years, the United States has started to widely use cloud platforms and services based on the following specialized platforms: aggregator platforms for primary acquisition and accumulation of agricultural information and applied platforms (management problems) [6]. The cloud interaction based on standards for all axes of the design space between these platforms makes them available for farms of all sizes, rather than for individual largest farms.

This standardization will affect the inter-industry relationships between manufacturing, processing, logistics, wholesale, and retail companies through the development of cloud technology for a direct sales model, when all the links in the chain can "see" each other, right down to the end user, as well as timeframes, amounts, range, and quality of demand. In this case, the principle of traceability is implemented, since the production allows migrating from the quality control phase after the product manufacture to the principle of operational control of all production operations. Thus, we can conclude that, with each new stage of the IS evolution, the number of companies subject to automation based on integration and digital standardization is growing, with entire industries and countries being involved in this process.

\section{Promising ERS digital platform as a prototype for a publicly available technology}

As stated above, at the end of the last century, P. David put forward the idea of a publicly available technology, the development of which would lead to the emergence of an entire range of new applied technologies. These technologies can be identified by the following features:

- the existence of a significant engineering potential for their development and implementation in new areas of human activity;

- a great variety of technologies and types of businesses where they can be used;

- manifestation of a high level of complementarity with new production technologies that arose on their basis;

- a proportional change in complementary assets in the form of material and engineering resources, management systems and structures, and human capital. 
In our opinion, we should expressly describe another significant feature: the economic one, which is the main driver for the emergence of publicly available technologies, called the technological breakthrough by $R$. Foster, as a result of which a new technology must significantly exceed the existing one in effectiveness [8].

Let us consider the presence or at least trends towards the manifestation of these features in the ERS technology at the present development stage of the digital economy. The integration process of both ISs and IRs is being implemented at a faster pace in industries with a small share of material and engineering resources and more structured information, e.g., in logistics, public services, banking sector, communications, etc. This will inevitably happen with the ERS technology, the data of which are required to consumers along the entire chain of their use. For this purpose, we will consider only those ERS data in various sectors of the national economy that are used in agriculture to assess the integration level of these data, as the ERS technology is the most advanced in this industry due to the spatial nature of its operations.

\subsection{ERS in cartography}

Inventory and mapping of fields, monitoring the boundaries of field working areas, solving problems of outlining the land use boundaries, and determining their surface areas for the subsequent development of farming systems.

\subsection{ERS in meteorology and climatology}

It was in meteorology that ERS data was first used. At early stages, ERS were used for this purpose only based on meteorological satellites. Images from space give a picture of the cloud cover structure and the circulation of air masses therein, showing the territorial heat balance, changes in the water steam composition, temperature in the atmosphere, the state of the ozone layer, and many other indicators. Figure 3 presents a unified ontological information model of crop production based on the integration of 240 functional tasks in crop production only [7]. Thus, ERS meteorological data are presented in 168 attributes of the "Atmosphere" section and in 46 attributes, in "Agrometeorological Parameters of the Field".

\subsection{ERS in hydrology}

In this case, the ERS technology is the basis for monitoring high water and floods; snow melting, water collection, and water intake processes; monitoring evaporation, precipitation, water quality and reserves in soil and snow; forecasting hydrological situations, etc.

\subsection{ERS in forestry}

In this sector, the ERS technology intersects with agriculture when monitoring forest plantations, in early detection of fires, pests, and tree diseases. In addition, due to the fact that the main objects in both industries are plants, their integration can be carried out using unified tools for automated interpretation of vegetation cover images based on various vegetation indices, e.g., the most common NDVI index that reflects the amount of photosynthetically active biomass. 


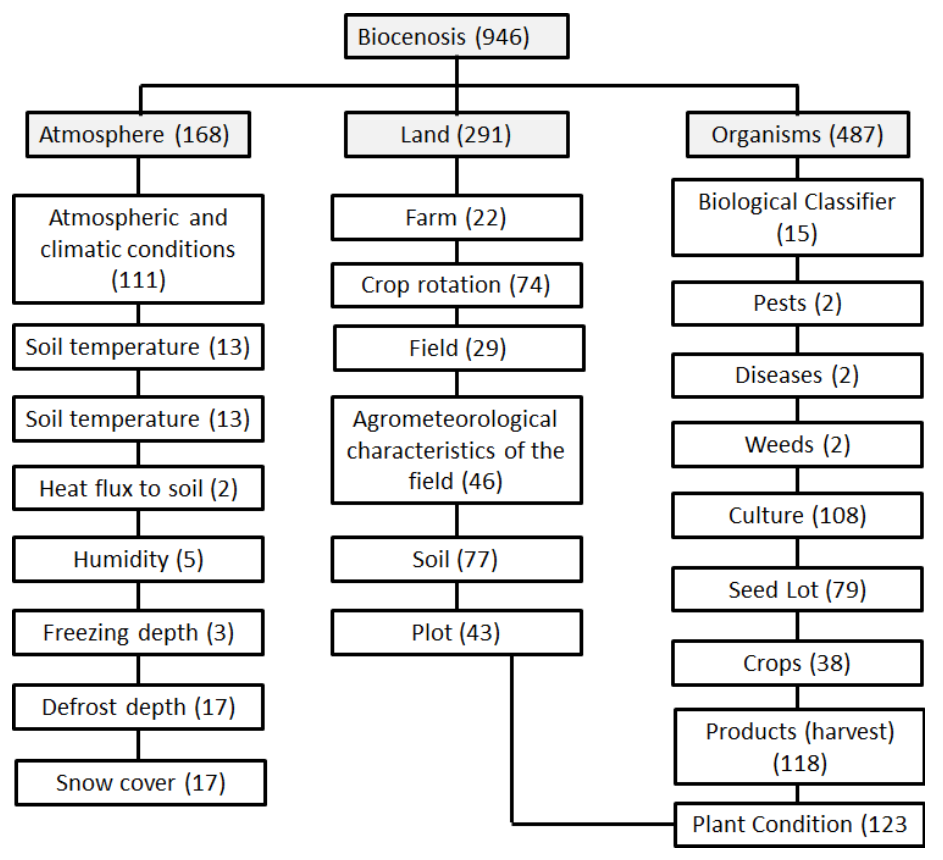

Figure 3: Enlarged conceptual information model of crop production.

\subsection{ERS in environment protection}

Since the anthropogenic nature of the adverse impact of humans on nature and agricultural lands is well tracked in ERS images, such information allows for carrying out an appropriate monitoring and forecasting of the environmental situation development followed by decisionmaking to minimize the consequences of such impact. Currently, agriculture, along with the manufacturing industry, transport, and power generation, is becoming one of the main pollutants of nature. In turn, environmental problems in agriculture are most manifested in crop production in the form of soil erosion, chemical pollution of land and water bodies, and a detrimental effect on several living species. The analysis of the ontological model (Figure 3) shows that more than half of its 946 indicators are related to ecology. Here are some examples. In the "Land" group (291 indicators), the "Crop Rotation" subgroup includes 30 indicators. The "Land Plot" subgroup of the "Field" group includes the following indicators: "Prohibiting Conditions for Using a Land Plot", "Geomorphological Parameters", "Land Reclamation Parameter", "Ground Water", "Salinization", "Soil", "Agrophysical Parameters", "Hydro-Physical Parameter", and "Soil Condition". Similarly, the "Crop" subgroup (108 indicators) includes the following indicators: "Ecological Group of a Variety", "Susceptibility to Diseases by Disease Types", "Susceptibility to Pests", etc.

\subsection{ERS in emergency situations}

In this case, the ERS technology is the basis for operational monitoring, forecasting, and assessment of the consequences of emergencies during floods and earthquakes, which will allow for making more competent decisions to eliminate the consequences of these disasters. 


\subsection{Calculation results using the mathematical model for creating an agricultural management DP}

Our analysis shows that all the above-discussed ERS industry data are reflected in a unified ontological information model of crop production based on the model for creating digital platforms (DP) for managing the agricultural economy [7]. Using this model, we could obtain a number of digital sub-platforms, which represent together a unified DP for agricultural management, the first of which is a cloud-based sub-platform for acquiring and storing operational primary accounting information of all companies in a unified database (Unified Primary Accounting Database, UPADB) in the following form: operation type and object, its implementation place, implementation subject, the operation date and time interval, the means of production involved, the amount and type of resource consumed. The next one is also a cloud platform based on a unified technological accounting database (UTADB) of all companies. Thus, Figure 3 shows the above-mention digital standard of this kind for all agricultural enterprises in the form of an ontological information model of crop production with identification of 240 functional management tasks and with a unified description of algorithms also for most agricultural companies (standard for management tasks). Such a DP, based on the above digital standards and on cloud technology for acquiring and storing information based on the same, provides fundamentally new opportunities for production management: it will allow for the development of unified production standard control systems; it can become a basis for planning and operational management, a tool for economic analysis; it will provide a reliable information component for the use of mathematical modeling, artificial intelligence, big data, and neural networks in various sections, starting from an individual land plot, head of livestock, means of production, an employee at every level up to the federal one; it will significantly simplify statistical recording and accounting.

Since, for several reasons, most of the national agricultural enterprises stopped developing their ISs at the second stage of the integration technology evolution, as a result of which, potentially, with $100 \%$ informatization in crop production only, we will get 4,800,000 ISs [9] countrywide, and upon transition to a unified DP for managing the AIC, its effectiveness will exceed thousands of times the effectiveness of existing technologies. Then, the condition of publicly available technologies in the form of a technological breakthrough will be fulfilled. It will also provide for implementation of all tasks of precision farming technology (PFT) in agriculture, which is most in demand worldwide and requires a combination of large amounts of data and technologies [10].

To give the ERS technology the features of a large space available for improvement and expansion to new areas of activity, we need to implement integration procedures for all ERS information, given that, at present, all ERS data is stored in heterogeneous structures of databases acquired and stored in various ground-based departmental systems and centers. This data is often transmitted to customers in the form of photos to be decrypted independently and at a high cost. The most effective way to get ready-made images for producers would be creating a unified Cloud Geographic Information System (CGIS) of ERS data with a special single body for their sectoral decryption followed by free transfer of ready-made solutions to users. Now, we have expectations for this: the Unified Geographically Distributed Information System (UGDIS) for ERS is being created with integrating all ERS information into a unified national geographic 


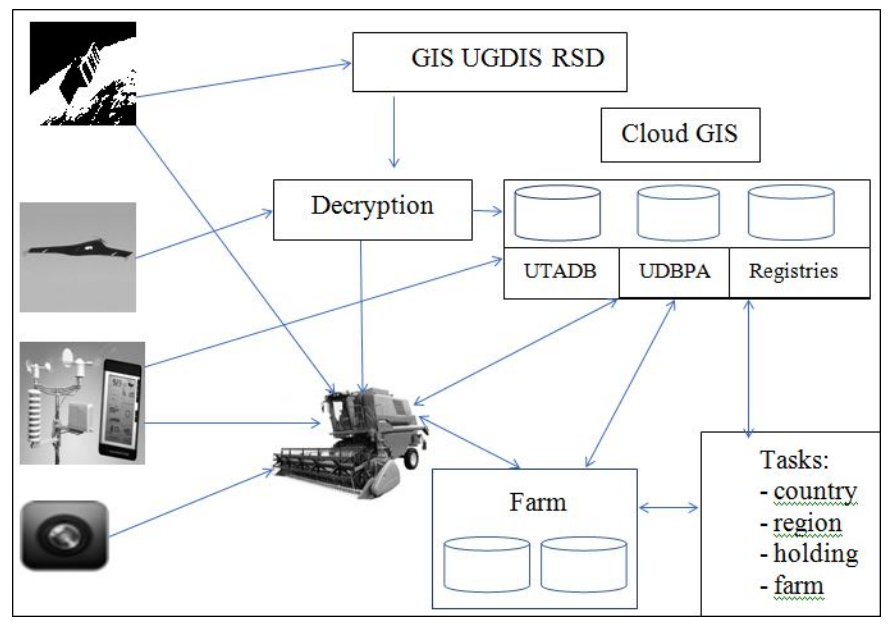

Figure 4: Diagram of a promising digital ERS platform in agriculture.

information space to be completed by 2025. This work is carried out in line with the plans of the Concept for the Development of the Russian Space System for ERS. Surely, it would also be desirable to create a similar center for decrypting images from increasingly popular drones, as well as from stationary ERS towers in fields, which would additionally reduce the cost of implementing ERS technology many times and enhance the efficiency of using these devices.

After its decryption in the new created centers, the ERS information should be acquired in a cloud GIS (CGIS), which should also acquire technological and primary accounting information, registers of all material, intellectual, and human resources of the industry. An example of this approach is the existing Integrated Administrative and Control System (IACS) in the EU, which acquires and stores information about lands and their users.

Further, information obtained from sources other than those listed above, as well as from gadgets, ground sensors and sensors installed on agricultural machines, should be acquired in the CGIS, and part of it should be transmitted directly back to the communication equipment of such machines (Figure 4). Therefore, the CGIS would store all data on all technological and accounting operations performed at each land plot, with each tool, and by each employee throughout the year. It would make it possible to track all movements of products, materials, and machines. This would provide a wide range of diverse products and business processes where the ERS technology could be applied (the second feature of a publicly available technology).

\section{Status and problems of digital transformation of agriculture in Russia}

To give the ERS technology other features of a publicly available technology, let us consider the experience with using individual ERS elements, as well as the situation around the additionality and complementarity of assets in the national agriculture. Currently, the expenses for ICT are becoming worldwide one of the main resource costs with a forecast to reach about USD 4 trillion in 2021 [11]. Although we must admit that our country is not ready for a full-scale digital 


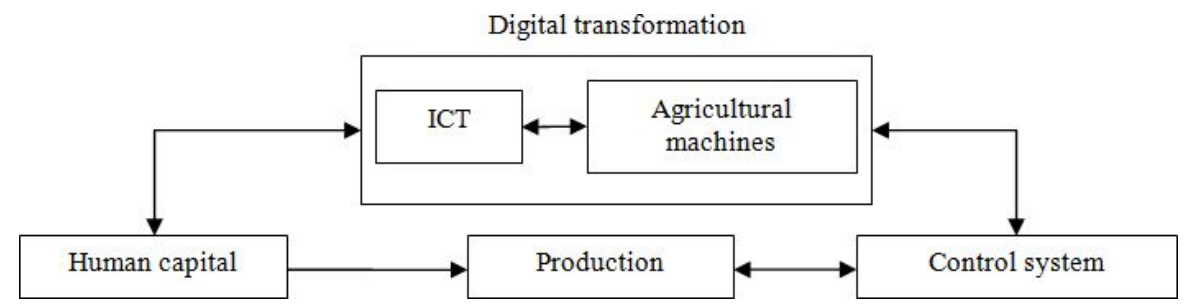

Figure 5: Complementary relations in the digital transformation of agricultural companies.

transformation of agriculture. This is evidenced both by the lack of integration processes in the digital economy program towards creating a DP for management of industries and the absence of the DE general designer with its own scientific and experimental industrial infrastructure, as well as a kind of digital feudalism due to transferring the program event executors' functions to several sectoral state-owned companies.

This is also evidenced by the poor social demand for comprehensive digitalization due to insufficient use of traditional factors to increase the production efficiency and the product quality in the industry. Finally, this is evidenced by the complementarity theory findings about the insufficient development level of other assets for the massive introduction of perfect digital technologies in the form of a material and technical infrastructure and human capital (Figure 5). Thus, the existing fleet of agricultural machinery in Russia is outworn: according to the calculations by researchers, up to $70 \%$ of machinery is physically worn out, whereas the share of obsolete equipment exceeds $90 \%$. According to the Ministry of Industry and Trade, the country's annual losses from this fact reach 15 million tons of grain, over 1 million tons of meat, about 7 million tons of milk, etc. [12].

In our country, several companies have started implementing certain new digital technologies, e.g., ERS, PFT, and artificial intelligence. However, the largely unsystematic nature of introducing these technologies against the background of the traditional conservatism in agriculture does not often provide the expected economic benefits. Let us analyze this situation.

Firstly, the Russian AIC does not adequately meet any of the prerequisites and factors for the successful implementation of any innovative idea in terms of digital transformation. There is no social demand due to the fact that the traditional factors of increasing the production efficiency and the product quality in the industry are still far from being exhausted. At the same time, as stated above, the AIC is involved in the digitalization process in the context of a general technological lag and technological dependence on the developed western countries. The losses are so significant that most farms will make a definite choice between a new Belarusian tractor costing from RUB 800,000 to 1,200,000, albeit unsuitable for digitalization, and, for example, the Yara N-sensor designed for precise control of plant nitrogen nutrition. In Germany, this sensor costs 25,000 euros, whereas in Russia its price reaches 60,000 euros, which is comparable to the price of a powerful Kirovets tractor. A similar situation has developed with the professional training/retraining of the necessary staff. Almost no agricultural university has introduced new specialties in recent years. But how can they be introduced, if the Ministry of Agriculture has not decided on the need and specialization of the required personnel, having stopped in approaches to the DE at the second IS evolution stage? 


\section{Influence of science on transforming methods of using ERS data into publicly available technology}

The economy digitalization has significantly expanded the range of problems to be solved not only in production, but also in science, allowing for purely theoretical scientific research to actively penetrate into production. This also requires appropriate integration mechanisms with production ISs based on digital standards and managerial structures.

For example, it has long been known that crop production is closely related to other sciences: physics, chemistry, botany, plant physiology, geology, soil science, meteorology, agricultural chemistry, soil management, agricultural land reclamation, breeding and seed production, entomology, phytopathology, mechanization, economics, organization, and planning of agricultural production. However, only now these disciplines are starting to actively penetrate through scientific research into the agro-industrial production. If, in the recent past, the patterns of influence on the development of plants were investigated mainly only for nitrogen, phosphorus, and potassium, at present, they have included other nutrients: calcium, magnesium, sulfur, chlorine, copper, manganese, iron, boron, molybdenum, zinc, carbon, hydrogen, oxygen, etc. In addition, attempts are being made to discover the patterns of obtaining nutrients not only in the form of fertilizers, but also through the symbiosis of higher plants with bacteria, the symbiosis of higher plants with fungi, providing the plant with its nutrient needs with the help of other organisms, the self-provision by a plant of its nutrient needs. It also became possible to study the mobilization or immobilization of individual nutrients in the soil through the control of chemical, physicochemical, and microbiological processes, biological properties of the plant itself, the dynamics of absorption of individual cations and anions during the growing process.

A wide coverage of new research methods is also recorded in animal husbandry; e.g., biotechnological methods in breeding, genetic engineering, and genomic editing of animals. The most active and more comprehensive research in this area is carried out in the developed western countries. Practical results of laboratory research entail the emergence of new or transformation of existing systems of machinery, production technologies, and work management.

Since scientific institutions all over the world use ontologically and functionally incompatible software, both in the scientific community and with development firms for implementing commercial ISs in agricultural companies, to accelerate the launch of modern developments in the $\mathrm{DE}$ era, developed countries began to create and finance innovation development centers which are considered as a new model of cooperation between government and business, on the one hand, and agricultural science, on the other hand [13]. Surely, when introducing scientific developments into production, we could follow the path of directly bringing together scientific institutions and production companies, but it will be too expensive and almost impossible due to the problem-oriented IS design and development.

Figure 6 shows the need for ontological modeling of scientific (set A) and production (set B) IRs when creating a unified digital platform for agriculture based on the principles of their integration. For this purpose, we need to do a lot of work on ontological modeling of all Research Institutes (RI: sets RI- $i, i=1, \ldots, N$ ), universities, production companies (we assume that there is a unified ontological production model, as considered below) with the identification of common intersecting parts based on the appropriate tools. 


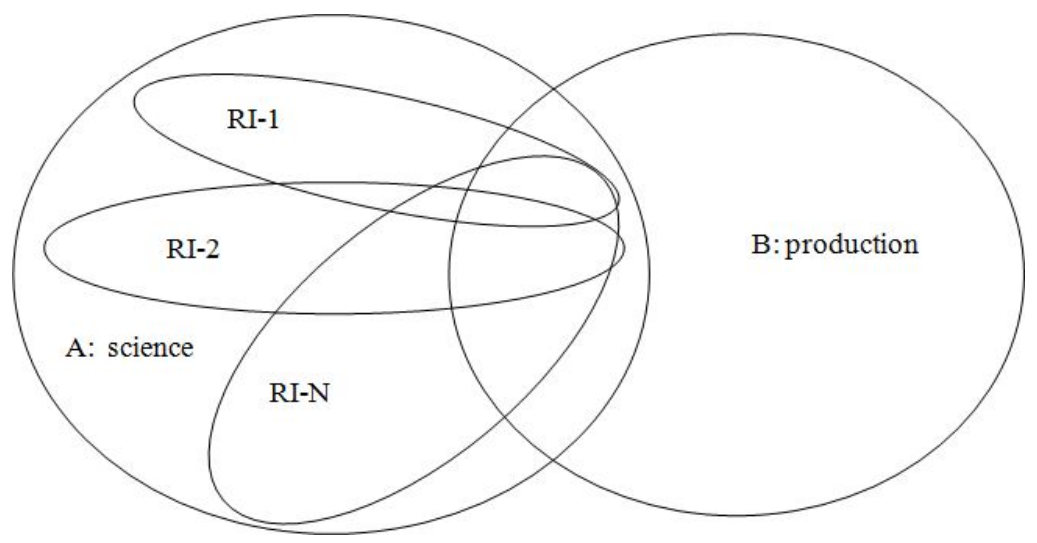

Figure 6: Need for the integration of agricultural IRs based on ontological modeling.

Whilst developed countries are actively creating innovation centers, in our country, on the contrary, such centers are being closed as part of the trend towards digital feudalism. As a result, with the tacit consent of the Russian Academy of Sciences and the Ministry of Agriculture, the All-Russian Scientific Research Institute of the Agro-Industrial Complex (VNIIK) was liquidated, that had developed uniform ontological models for most types of farms, and on the eve of adopting the DE Program and with the consent of the Ministry of Education, the Institute of Agrarian Problems and Informatics (VIAPI), at the suggestion of its director, closed the research topics for the sectoral DE. Upon the liquidation of VNIIK, A.V. Petrikov, the VIAPI's director and an ardent opponent of digitalization, ordered to take out to a landfill two trucks of technical working projects for informatization based on IS standardization and ontological modeling for main types of AIC companies. In the current situation with the industry digitalization, the Ministry of Agriculture is unable, in principle, to reproduce these projects. As a Deputy Minister of Agriculture, he is engaged in the manufacture of hacks in the field of informatization based on original design, carried out by organizations far from science, from a systematic approach; he argues that research and development in the digital economy is not required in the AIC: this should be done by commissioning and market companies; accordingly, IT departments in agricultural universities must be closed. This causes great damage to one of the key complementary assets - the human capital, the social and educational level of future executors and consumers of digital agriculture, not to mention the transformation of technologies for agricultural management processes. As a result of the lack of innovation centers in Russia, there has been a tendency to form their own scientific departments with large agro-industrial companies, which entails an accelerated immersion of all agriculture in a kind of digital feudalism, both in agricultural science and in production [14], while excluding science from the national innovative development.

To overcome digital feudalism in the agrarian science, Russia should take into account that the digital technology is being improved worldwide in many respects by trial and error, so rapidly that the economy does not have time to test the most effective, well-established production technologies that would be understandable and acceptable for producers. The latter should evaluate in practice the effectiveness of their use over a certain period of time within the range 
of different conditions of production that they can understand. In order to obtain reliable, both quantitative and qualitative indicators of the digital technology effectiveness, the Ministry of Agriculture of Russia, similarly to developed countries, should focus its efforts on the integrated development of the most advanced digital technologies at several reference sites - sandboxes at different territorial levels, while equipping them with modern ICT, sensors, instruments, process equipment and a machine and tractor fleet, both compatible with each other and adapted to various digital technologies covering all possible areas of their development in the world, followed by a massive deployment of the most effective of them throughout the country. In the case where the results of modeling the AIC's readiness for digital transformation show an insufficient level of development of complementary assets for a massive introduction of ready-made digital technology, advanced development studies in this area should be carried out at reference sites, to be at the level of the leading countries of the world, with the issuance of the necessary recommendations and regulatory restrictions for those companies that can implement comprehensive digital technologies.

\section{Conclusion}

There is a long-known statement that implementing any scientific innovation needs three requirements to be met: there must be a "social demand" for it; there must be an appropriate technical level achieved to translate the innovation into practice; and there must be the necessary social and educational level of potential executors and consumers of such innovation. Since these requirements are not fully met in Russia, moreover, in the absence of sufficient investment, we see a possible solution in the consistent implementation of the promising digital ERS platform based on reference sites, which will create prerequisites for its transformation into a system of scientifically sound infrastructure technologies, which will be publicly available for the whole country. Such an integrated approach will multiply reduce the costs of the industry digitalization while significantly increasing the efficiency of its technology.

\section{Acknowledgments}

This work was supported by RFBR (grant No. 20-07-00836).

\section{References}

[1] Raikov A. Cognitive semantics of artificial intelligence: A new perspective. Springer Sinbreakthroughore, Topics: Computational Intelligence XVII. 2021. DOI:10.1007/978-98133-6750-0.

[2] David P.A. The dynamo and the computer: An historical perspective on the modern productivity paradox // The American Economic Review. American Economic Association, 1990. Vol. 80(2). P. 355-361.

[3] Efimenko I.V., Khoroshevsky V.F. Ontological modeling of the economy of enterprises and industries in modern Russia: Part 1. Ontological modeling: Approaches, models, methods, tools, solutions. M.: Ed. House of the Higher School of Economics, 2011. 
[4] Milgrom P., Roberts J. The economics of modern manufacturing: Technology, strategy and organization // American Economic Review. 1990. Vol. 80(3). P. 511-528.

[5] Brooks F. The mythical man-month or how software systems are created. SPb.: SymbolPlus, 2001.

[6] J'son \& Partners Consulting. Analysis of the market of cloud IoT platforms and applications for digital agriculture in the world and prospects in Russia. Available at: https://json.tv/en/ict_telecom_analytics_view/ analysis-of-the-market-of-cloud-iot-platforms-and-applications-for-digital-agriculturein-the-world-and-prospects-in-russia.

[7] Ereshko F.I., Medennikov V.I., Muratova L.G. Modeling of a digital platform in agriculture // IEEE Xplore Digital Library. Eleventh International Conference Management of Large-Scale System Development (MLSD). Moscow, Russia, 2018. DOI:10.1109/MLSD.2018.8551894.

[8] Foster R. Renovation of production: The attackers win. Moscow: Progress, 1987.

[9] Kulba V., Medennikov V. A model of the Russia's agriculture readiness for digital transformation // IEEE Xplore Digital Library. 2020. DOI:10.1109/MLSD49919.2020.9247704.

[10] Huang Y., Chen Z., Yu T., Huang X., Gu X. Agricultural remote sensing big data: Management and applications // Journal of Integrative Agriculture. 2018. Vol. 17(9). P. 1915-1931. DOI:10.1016/S2095-3119(17)61859-8.

[11] Gartner: Global IT spending on software and services - including cloud - on the rise. 2020. Available at: https://www.crn.com/slide-shows/channel-programs/ gartner-global-it-spending-on-software-and-services-including-cloud-on-the-rise.

[12] State of the MTP. 2021. Available at: http://www.agroyug.ru/news/id-28566 (accessed April 4, 2021).

[13] Raikov A.N., Medennikov V.I. Analysis of the experience of digital transformation in the world for agriculture in Russia // Proceedings of the III All-Russian Scientific and Practical Conference "Trends in the Development of the Internet and the Digital Economy". Simferopol-Alushta. SP Zueva T.V. 2020. P. 57-62.

[14] Medennikov V.I. Complementary dependences of science and business are a necessary condition for the success of the digitalization of the agrarian economy // Digital Economy. 2020. Vol. 3(11). P. 41-54. 